\title{
Detection of Anti-viral Drug Riamilovir and Herbicides in Aqueous Media by Using Pyrene-based Fluorescent Chemosensors
}

\author{
I.S. Kovalev ${ }^{\text {a }}$, L.K. Sadieva ${ }^{\mathrm{a}, \mathrm{b},{ }^{*}}$, O.S. Taniya ${ }^{\mathrm{a}, \mathrm{b}}$, D.S. Kopchuk ${ }^{\mathrm{a}, \mathrm{b}}$, \\ G.V. Zyryanov ${ }^{\mathrm{a}, \mathrm{b}}$, E.N. Ulomsky ${ }^{\mathrm{a}, \mathrm{b}}$, V.L. Rusinov ${ }^{\mathrm{a}, \mathrm{b}}$, O.N. Chupakhin ${ }^{\mathrm{a}, \mathrm{b}}$ \\ a: Ural Federal University, 19 Mira St., Yekaterinburg 620002, Russia \\ b: Postovsky Institute of Organic Synthesis, Ural Branch of the Russian Academy of Sciences, \\ 22 S. Kovalevskoi / 20 Akademicheskaya St., Yekaterinburg 620219, Russia \\ * Corresponding author: leilasad@yandex.ru \\ This short communication (letter) belongs to the regular issue.
}

(C) 2021, The Authors. This article is published in open access form under the terms and conditions of the Creative Commons Attribution (CC BY) license (http://creativecommons.org/licenses/by/4.0/).

\begin{abstract}
Two ethyleneglycol esters of 1-pyrene carboxylic acid were studied as chemosensors for the fluorescence "turn-off" detection of two nitro-containing analytes, such as antiviral drug Riamilovir (Triazavirin $(\circledR)$ and herbicidal agent dinitro-ortho-cresol (DNOC). In both cases the dramatic fluorescence quenching was observed with quenching constants as high as $3 \cdot 10^{4} \mathrm{M}^{-1}$ and limits of detection (LOD) as low as $100 \mathrm{ppb}$.
\end{abstract}

\section{Keywords}

COVID-19

Riamilovir (Triazavirin ${ }^{\circledR}$ )

DNOC

detection in aqueous media

chemical sensors

pyrene-based fluorophores

fluorescence quenching

Received: 19.04.2021

Revised: 30.04.2021

Accepted: 18.05.2021

Available online: 20.05.2021

\section{Introduction}

One of the scourges of modern civilization is the coronavirus (SARS-CoV-2) pandemic that broke out in the end of the 2019. Despite the fact that the antiviral drug Riamilovir (Triazavirin $(\mathbb{R})$ is not a specific drug against SARSCoV-2, it has successfully shown itself among other drugs in reducing the incidence of respiratory, cardiac, hepatic, renal and other complications, associated with coronavirus infection (COVID-19) [1,2]. For the pharmacokinetic studies of this drug as well as other ones, it is very important to determine the fate of these substances, administered to a living organism. Once drugs are administered their concentration in target organs or biological liquids is changed. Fluorescence-based methods are the robust and convenient methods of measuring drug concentration in the biological (water-based) liquids and target organs $[3,4]$.

In addition to coronavirus infection, the problem of soil, air and rain pollution with herbicides and their decay products, has long been an acute problem [5]. Despite the fact that at present in Europe and the United States the use of such herbicide as Dinitro-ortho-cresol (DNOC) is abandoned, accumulated over the years of previous use, it is still present $[5,6]$. DNOC has been identified in at least 56 of the 1854 hazardous waste sites that have been proposed for inclusion on the EPA National Priorities List (NPL) [6]. It is also still widely used in Russia and other countries.

In this manuscript we would like to report our study of sensory abilities of the pyrene-based polyethyleneglycol water-soluble fluorescent "turn-off" chemosensors toward nitro-containing drug Riamilovir and herbicide DNOC.

\section{Experimental}

Chemosensors 1-2 (see Fig. 1) were obtained as reported earlier [7]. Starting materials are commercially available. Fluorescence titration experiments were carried out by using the Horiba-Fluoromax-4 spectrofluorometer (USA). Solutions of sensors 1-2 with concentration $10^{-6} \mathrm{M}$ in $\mathrm{H}_{2} \mathrm{O}$ : THF (99.9 : $0.1(\mathrm{v} / \mathrm{v})$ ) and solutions of quenchers with concentration $10^{-4} \mathrm{M}$ in water (Riamilovir) and in acetonitrile (DNOC) were prepared. Next, fluorescence quenching 
<smiles>O=C(OCCOc1ccccc1)c1ccc2ccc3cccc4ccc1c2c34</smiles>

Fig.1 Structure of chemosensors 1-2

was carried out via the method of Single Point [8]. The solution of sensor by volume of $3 \mathrm{ml}$ was placed in quartz cuvette and intensity of its fluorescence was measured. After that 15 aliquots of solution of quencher (volume of each aliquot was $10 \mathrm{mkl}$ ) were added into cuvette one by one. After each addition of quencher, fluorescence intensity was measured.

Analysis of fluorescence quenching was performed on the basis of a Stern-Volmer equation of static quenching (1):

$$
\frac{I_{0}}{I}=1+K_{\mathrm{SV}}[\mathrm{Q}] .
$$
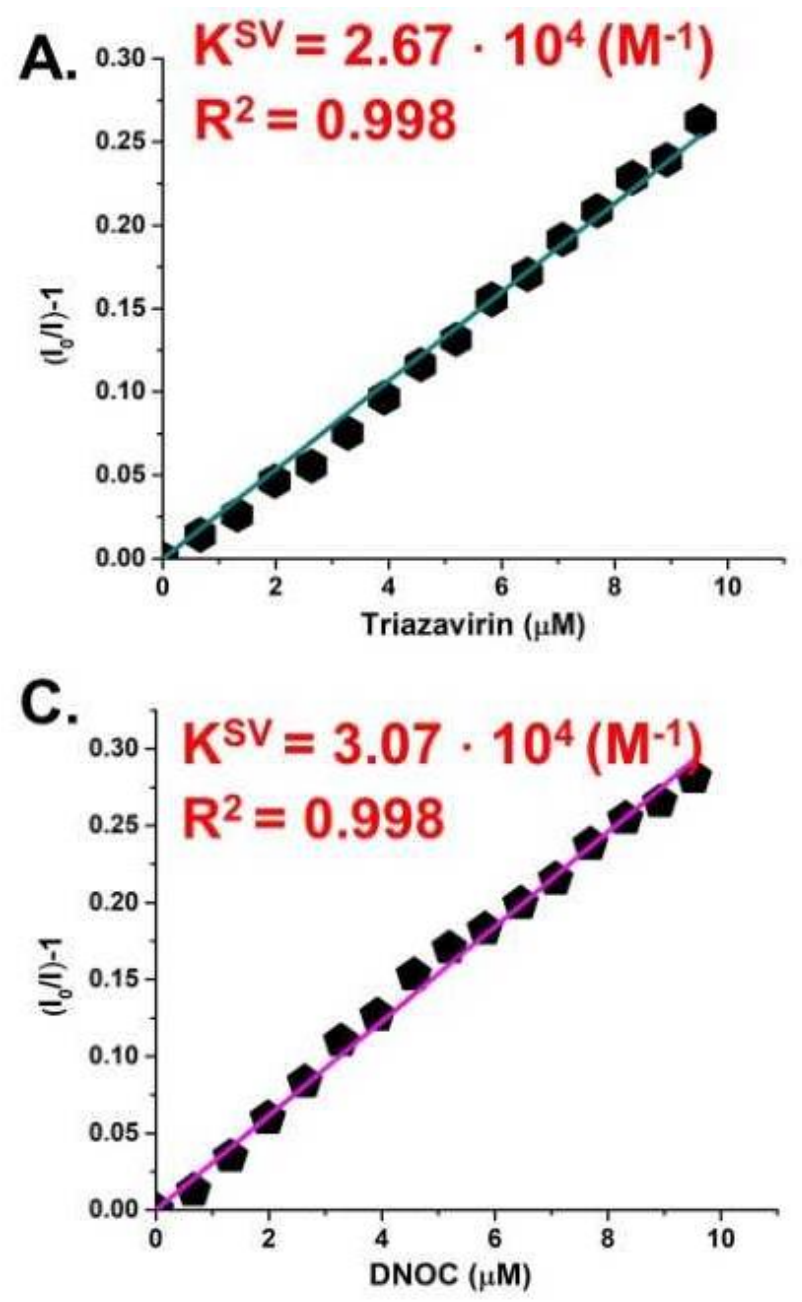

The Stern-Volmer constants $\left(K_{\mathrm{sv}}\right)$ were calculated as the slope of the intensity plot $\left(\left(\left(I_{0} / I\right)-1\right)\right)$ versus the concentration of the quencher ([Q]).

\section{Results and Discussion}

As water soluble chemosensors, two pyrene-based chemosensors 1-2 (Fig. 1) were selected, and their synthesis and photophysical properties were reported earlier [7]. Based on these previous studies, chemosensors 1-2 have exhibited high sensitivity toward some common nitroexplosives, such as 2,4,6-trinitrotoluene (TNT) and pentaerythritol tetranitrate (PETN) in aqueous media. So, we expected that these molecules will be suitable candidates for the detection of nitro-containing Riamilovir and DNOC.

To study sensory abilities of sensors 1-2 towards the abovementioned nitro-analytes, fluorescence quenching titration was carried out. The fluorescence response was quantitatively determined via the Stern-Volmer static quenching model, according to Eq. (1).

The Stern-Volmer constant values for Riamilovir were calculated to be as high as $K_{\mathrm{sv}}=2.67 \cdot 10^{4} \mathrm{M}^{-1}$ and $2.28 \cdot 10^{4} \mathrm{M}^{-1}$ for the sensors 1 and 2, respectively, and, based on the linearity of the Stern-Volmer plots, the static quenching (Table 1, Fig. 2A,B) was suggested.
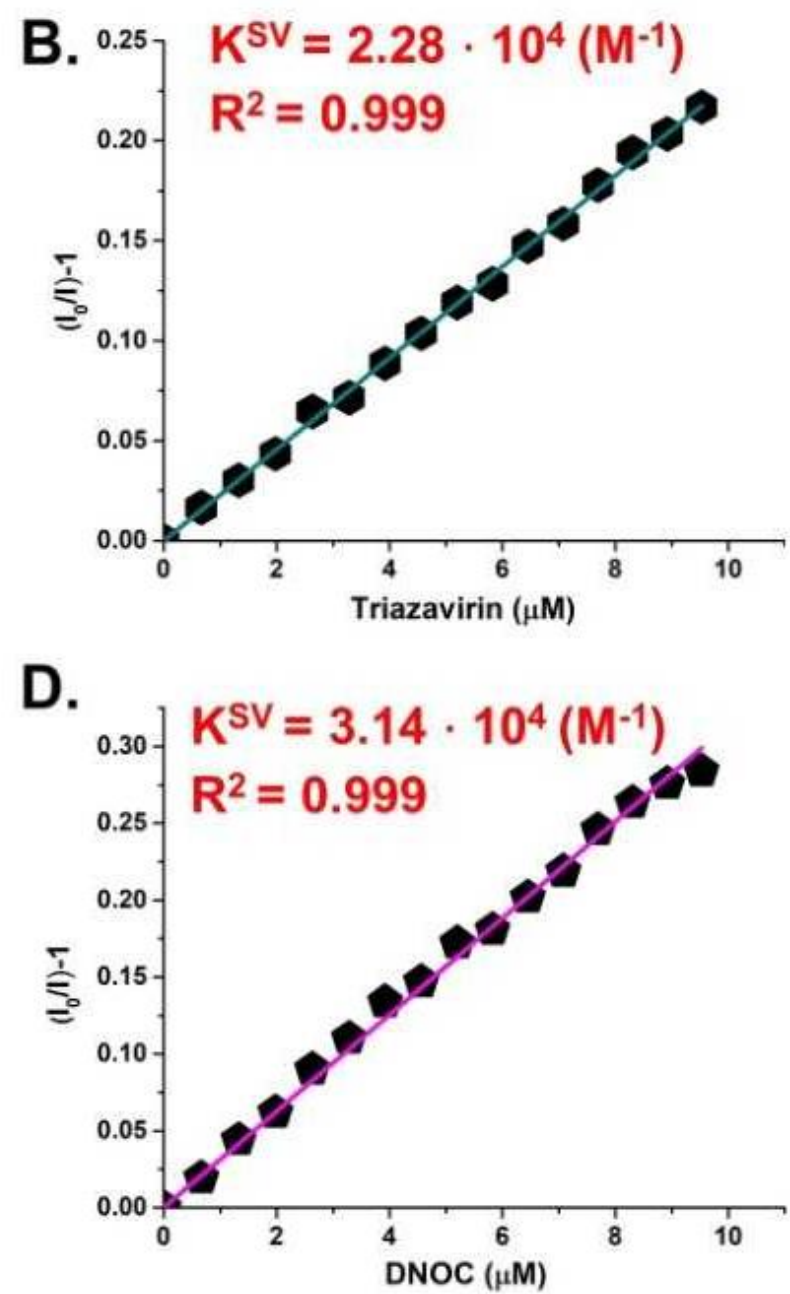

Fig. 2 Stern-Volmer plots of emission quenching for sensors 1 (A, C) and 2 (B, D): points - experimental data, lines - linear fitting results 
Table 1 Summary of the Stern-Volmer rate constants and LOD for the chemosensors 1-2

\begin{tabular}{ccccc}
\hline Sensor & $K_{\mathrm{SV}}{ }^{\text {Riamil. }}, \mathrm{M}^{-1}$ & $K_{\mathrm{SV}}{ }^{\mathrm{DNOC}}, \mathrm{M}^{-1}$ & $\begin{array}{c}\mathrm{LOD}^{\text {Riamil. }} \\
\mathrm{ppb}\end{array}$ & $\begin{array}{c}\mathrm{LOD}^{\mathrm{DNOC}} \\
\mathrm{ppb}\end{array}$ \\
\hline 1 & $2.67 \cdot 10^{4}$ & $3.07 \cdot 10^{4}$ & 101 & 122 \\
2 & $2.28 \cdot 10^{4}$ & $3.14 \cdot 10^{4}$ & 252 & 223 \\
\hline
\end{tabular}

Under similar conditions, DNOC caused a slightly stronger response, which can be seen based on higher values of Stern-Volmer constants, such as $K_{\mathrm{sv}}=3.07 \cdot 10^{4} \mathrm{M}^{-1}$ (for the sensor 1) and $K_{\mathrm{sv}}=3.14 \cdot 10^{4} \mathrm{M}^{-1}$ (for the sensor 2) (Table 1). Again, linearity of Stern-Volmer plots was observed.

In addition to linear behavior of Stern-Volmer plots, high values of the coefficient of determination $\left(R^{2}\right)$ were obtained (Fig. 2). Thus, the prevalence of only one quenching mechanism, such as static quenching, in all the cases was suggested.

For all titration experiments, limits of detection (LOD) were calculated by using previously reported methods [9]. LOD values are collected in Table 1.

\section{Conclusions}

Ethyleneglycol esters of 1-pyrene carboxylic acid were found to be promising chemosensors for the fluorescence "turn-off" detection of nitro-containing drugs, such as Riamilovir, and ecotoxicants, such as dinitro-ortho-cresol, in aqueous solutions. In all the cases, dramatic fluorescence quenching and high quenching constants $\left(2.28 \cdot 10^{4}\right.$ $3.14 \cdot 10^{4} \mathrm{M}^{-1}$ ) were observed.

\section{Acknowledgements}

This work was supported by the Russian Foundation for Basic Research (Project № 19-33-90155).

\section{References}

1. Wu X, Yu K, Wang Y, Xu W, Ma H, Hou Y, et al. Efficacy and Safety of Triazavirin Therapy for Coronavirus Disease 2019: A Pilot Randomized Controlled Trial. Engineering. 2020;6(10):1185-91. doi:10.1016/j.eng.2020.08.011

2. Sabitov AU, Belousov VV, Edin AS, Oleinichenko EV, Gladunova EP, Tikhonova EP, et al. Practical experience of using riamilovir in treatment of patients with moderate COVID-19. Antibiotiki i Khimioterapiya. 2020;65(7-8):27-30. Russian. doi:10.37489/0235-2990-2020-65-7-8-27-30

3. Ayoob AM, Peppi M, Tandon V, Langer R, Borenstein JT. A fluorescence-based imaging approach to pharmacokinetic analysis of intracochlear drug delivery.

Hear Res. 2018;368:41-8. doi:10.1016/j.heares.2018.03.026

4. Kuneš M, Květina J, Maláková J, Bureš J, Kopáčová M, Rejchrt S. Pharmacokinetics and organ distribution of fluorescein in experimental pigs: An input study for confocal laser endomicroscopy of the gastrointestinal tract. Neuroendocrinol Lett [Internet]. 2010;31(Suppl. 2):57-61. Available from: https://www.nel.edu/userfiles/articlesnew/NEL31S210A09.p $\underline{\mathrm{df}}$

5. Lyle K. Environmental Health Criteria 220 DINITRO-orthoCRESOL [Internet]. 200o. Available from: https://www.who.int/ipcs/publications/ehc/en/ehc220.pdf

6. Toxicological Profile for Dinitrocresols. ATSDR's Toxicological Profiles [Internet]. 2018. Available from: https://www.atsdr.cdc.gov/toxprofiles/tp63.pdf

7. Sadieva LK, Taniya OS, Kovalev IS, Kopchuk DS, Zyryanov GV, Rusinov VL, et al. Polietilenglikolevyye efiry piren-1karbonovoy kisloty: sintez i fotofizicheskiye issledovaniya [Polyethylene glycol esters of 1-Pyrenecarboxylic acid: synthesis and photophysical studies]. Izv Acad Nauk. 2021;4. Forthcoming 2021.

8. DAS-6 Operation Manual [Internet]. Horiba Scientific; 117 p. Available from:

https://www.horiba.com/fileadmin/uploads/Scientific/Down loads/UserArea/Fluorescence/Manuals/DAS67 Manual.pdf

9. Shrivastava A, Gupta V. Methods for the determination of limit of detection and limit of quantitation of the analytical methods. Chronicles Young Sci. 2011;2(1):21. doi: $10.4103 / 2229-5186.79345$ 